\title{
Prevalence and Factors Associated with the Depressive and Anxiety Symptoms amongst Antenatal Women
}

\author{
Arifin S.R.M. ${ }^{a}$, Ismail A.S. ${ }^{b}$, Samsudin S. ${ }^{c}$, Hassan N.A ${ }^{c}$, Wan Mamat W.H. ${ }^{a}$ \\ ${ }^{a}$ Kulliyyah of Nursing, International Islamic University Malaysia, Pahang, Malaysia. \\ ${ }^{b}$ Sunway Medical Centre, Bandar Sunway, Petaling Jaya, Selangor \\ ${ }^{c}$ Kulliyyah of Medicine, International Islamic University Malaysia, Pahang, Malaysia.
}

\section{ABSTRACT}

INTRODUCTION: There is a wide range of antenatal mental disorder prevalence, including depression, anxiety and worry across countries. Studies to determine the association between sociodemographic factors, social support and antenatal mental health disorders have since produced inconsistent results. The aim of this study was to determine the prevalence and factors associated with antenatal anxiety, worry and depression among pregnant women. MATERIALS AND METHODS: A total of 262 women who attended any of four Maternal and Child Health clinics in Kuantan, Pahang had participated in this cross-sectional study. The social support, depression, anxiety and worry were measured using the Multidimensional Scale of Perceived Social Support (MSPSS), the Edinburgh Postnatal Depression Scale (EPDS), State-trait Anxiety Inventory (STAI) and Cambridge Worry Scale (CWS), respectively. RESULTS: Of these women, 20.2\% had depressive symptoms, $22.5 \%$ had antenatal anxiety, and $79 \%$ had antenatal worry. Women with lower education background were at risk of antenatal depression whereas working and first-time mothers were at risk of experiencing worry in pregnancy. This study has proven that social support plays a significant role in alleviating worry during pregnancy. CONCLUSION: Considering that the high level of worry in pregnancy could result in negative pregnancy outcomes and postnatal depression, there should be a screening tool used to measure psychological wellbeing of the pregnant mother within the clinical practice. The element of social support should be included in the intervention targeting women with lower educational level, primiparous and working mothers.

KEYWORDS: Antenatal, Depression, Anxiety, Worry, Pregnant

\section{INTRODUCTION}

Pregnant women are vulnerable to developing antenatal mental disorders due to the physical and psychological changes in their body. ${ }^{1}$ The most common antenatal mental disorders during pregnancy are depression, anxiety and worry. ${ }^{2}$ Across countries, a wide range of prevalence of these disorders have been reported. While the prevalence of antenatal anxiety varies from $16 \%$ -

\section{Corresponding Author:}

Asst. Prof. Dr. Siti Roshaidai Mohd Arifin Department of Special Care Nursing Kulliyyah of Nursing, International Islamic University Malaysia, 25200 Kuantan, Pahang, Malaysia

Tel No : +60199814261

E-mail : roshaidai@iium.edu.my
$47 \%, 3-6$ antenatal depression prevalence ranged from $15 \%$ to $65 \%$ worldwide. ${ }^{7}$ Reasons of the wide range of prevalence were associated with the lack of available and reliable data on antenatal mental disorders, especially in low-middle income countries (LMIC).

Various sociodemographic, obstetrics and cultural factors have been identified to be associated with depressive and anxiety symptoms. For example, antenatal depressive symptoms was found to be associated with maternal age, maternal education, parity, number of pregnancies, gestational age, complications during pregnancy and childbirth, unplanned pregnancy, previous psychiatric diagnosis, perceived stress, abortion thoughts, smoking, negative life events, intimate partner 
violence, maternal history of childhood abuse, having household debt and lack of social support. ${ }^{8-13}$ Antenatal anxiety symptoms was significantly associated with maternal education, socioeconomic disadvantages, perceived stress, family history of depression or anxiety, intimate partner victimization, substance abuse, complication during pregnancy, disharmony in family relationship and life satisfaction. 5,6,12

Whilst antenatal depression and anxiety are well studied in various population and countries, less attention has been given to worry during pregnancy despite it being one of the common antenatal mental disorders. Throughout pregnancy, women may worry for various reasons, such as concerns about the baby's health, complications of pregnancy and childbirth, first-time pregnancy and being pregnant at an early or advanced age. ${ }^{14-15}$ In Malaysia, although studies have found that $23.4 \%$ of antenatal women had the anxiety symptoms and $20.3 \%$ experienced depressive symptoms, there is no study on the prevalence of worry during pregnancy. 13,16

Furthermore, previous studies to determine the association between depressive and anxiety symptoms and social support have since produced inconsistent results. For instance, studies in Pakistan ${ }^{17}$ and Ethopia ${ }^{18}$ found no significant relationship between social support during pregnancy with antenatal depressive symptoms, but studies in Turkey ${ }^{19}$ and Australia ${ }^{20}$ revealed a contradicting finding.

In Malaysia, social support is expected to be high for antenatal women as pregnancy is considered as an opportunity to expand the family lineage. ${ }^{13}$ However, in recent years, young people moved from rural to urban areas for a better career development and life improvement, exposing antenatal women to lack of social support from their close family members and probably leading to depression and anxiety. Although there was a study conducted on the association between social support and antenatal depression in Malaysia, ${ }^{13}$ its association with other types of antenatal mental disorders such as anxiety and worry symptoms remained unclear. Therefore, this study aimed to determine the factors associated with depressive, anxiety and worry symptoms among antenatal women.

\section{MATERIALS AND METHODS}

A quantitative cross-sectional survey using a questionnaire was conducted at four purposively selected Maternal and Child Health clinics $(\mathrm{MCH})$ in Pahang to recruit 262 antenatal women from 1st March to 30th April 2018. The sample size was calculated by using Raosoft sample size calculator. The margin of error is $5 \%$, confidence interval of $90 \%$ and response rate of $50 \%$. The recommended sample size of this study was 267 .

The antenatal women were recruited by approaching women who attended for antenatal check-up in the $\mathrm{MCH}$ clinics based on inclusive and exclusive criteria. The inclusion criteria were: (a) Malaysian nationals, (b) any stage of pregnancy and (c) able to understand Malay or English. Women with underlying psychiatric disorders were excluded from this study. Eligible women were given a set of self-administered questionnaires.

The self-administered questionnaire had five parts: Parts A, B, C, D and E. Part A consisted of sociodemographic data such as age, race, marital status, educational level, employment status, number of birth and gestational age. Part B measured the social support using the validated Malay version of The Multidimensional Scale of Perceived Social Support (MSPSS). ${ }^{21}$ The MSPSS questionnaire was developed by Zimet, Dahlem, Zimet and Farley. ${ }^{22}$

This part comprised of 12 items scored on a 7-point Likert scale ranging from 1 (very strongly disagree) to 7 (very strongly agree). Part C evaluated the depression symptoms using the Malay version of The Edinburgh Depression Scale (EPDS). ${ }^{23}$ The EPDS was developed by Cox et al. (1987). ${ }^{24}$ The questionnaire consisted of 10 items scored on a 4-point Likert scale ranging from 0 (never) to 3 (always). Part D evaluated the anxiety using the validated Malay version of The State Trait Anxiety Inventory (STAI). ${ }^{25}$ The STAI was developed by Spielberger in $1972 .{ }^{23}$

This part consisted of 20 items scored on a 4-point Likert scale ranging from 1 (not at all) to 4 (very much so) to assess the participants' emotional state at that time. Part E measured the level of worry during 
pregnancy using the validated Malay version of The Cambridge Worry Scale (CWS). ${ }^{26}$ The CWS was developed by Green et al. in 2003. ${ }^{26}$ The questionnaire consisted of 16 items scored on a 6-point Likert scale ranging from 0 (not a worry) to 5 (major worry) to assess the participants' level of worry during pregnancy.

All data were analysed using the Statistical Package Social Science (SPSS) software (version 20.0). Descriptive characteristics of the participants were presented as frequency, percentage, mean and standard deviation.

Table 1: Sociodemographic and clinical characteristics of the respondents

\begin{tabular}{|c|c|c|c|}
\hline Variables & & $\mathrm{n}$ & $\%$ \\
\hline \multirow[t]{5}{*}{ Age } & $<20$ years & 5 & 1.9 \\
\hline & $20-30$ years & 110 & 42.0 \\
\hline & $30-40$ years & 126 & 48.1 \\
\hline & $>40$ years & 21 & 8.0 \\
\hline & Average (SD) & \multicolumn{2}{|c|}{$\begin{array}{l}30 \text { years } \\
(5.40)\end{array}$} \\
\hline \multirow[t]{3}{*}{ Race } & Malay & 255 & 97.3 \\
\hline & Chinese & 5 & 1.9 \\
\hline & Indian & 2 & 0.8 \\
\hline \multirow[t]{3}{*}{ Marital status } & Single & 3 & 1.1 \\
\hline & Married & 256 & 97.7 \\
\hline & Divorced & 3 & 1.1 \\
\hline \multirow[t]{3}{*}{ Education } & Primary Level & 8 & 3.1 \\
\hline & Secondary Level & 109 & 41.6 \\
\hline & $\begin{array}{l}\text { College/University } \\
\text { Level }\end{array}$ & 145 & 55.3 \\
\hline \multirow[t]{2}{*}{$\begin{array}{l}\text { Employment } \\
\text { Status }\end{array}$} & Employed & 138 & 52.7 \\
\hline & Unemployed & 124 & 47.3 \\
\hline \multirow[t]{3}{*}{$\begin{array}{l}\text { Occupation } \\
\text { Sector }\end{array}$} & $\begin{array}{l}\text { Government } \\
\text { Sector }\end{array}$ & 68 & 26 \\
\hline & Private Sector & 70 & 26.7 \\
\hline & Not Working & 124 & 47.3 \\
\hline \multirow[t]{3}{*}{ Number of Birth } & Once & 108 & 41.2 \\
\hline & 2-4 times & 130 & 49.6 \\
\hline & $>5$ times & 24 & 9.2 \\
\hline \multirow[t]{2}{*}{ Gestation } & $<37$ weeks & 95 & 36.3 \\
\hline & $37-40$ weeks & 123 & 46.9 \\
\hline
\end{tabular}

The Fisher's exact test was performed to determine the relationship between the sociodemographic and social support with the antenatal mental health disorders. Statistical tests were two-sided, and p-values of less than 0.05 were considered significant.

\section{RESULTS}

A total of 262 respondents were included in the final analysis (Table 1). Results indicated that 20.2\% had symptoms of depression, $22.5 \%$ had antenatal anxiety and $79 \%$ had antenatal worry (Table 2 ).

Table 2: Prevalence of antenatal mental disorders

\begin{tabular}{lllll}
\hline & Presence & \multicolumn{3}{c}{ Absence } \\
& $\mathbf{n}$ & $\mathbf{0}$ & $\mathbf{n}$ & $\mathbf{0}$ \\
\hline Depressive & 53 & 20.2 & 209 & 79.8 \\
Anxiety & 59 & 22.5 & 203 & 77.5 \\
Worry & 207 & 79.0 & 55 & 21.0 \\
\hline
\end{tabular}

A logistics regression analysis was employed to predict the probability of factors affecting antenatal mental health disorders among antenatal Malaysian women. In this study, three dichotomous dependent variables were tested: Depression (1-Presence, 0-Absence), Anxiety (1Presence, 0-Absence) and Worry (1-Major worry, 0-Not worry). The dichotomous predictor variables were the respondent's age, race, marital status, education level, occupation status, number of births, and gestation.

Table 3 shows that the education level had positive significant values to the risk of depression. The odds ratio (OR) reflected that the respondents from lower education background were 2.738 times more likely than those from higher education background to experience depression. Other predictors, however showed insignificant value $(p>.05)$ and therefore did not contribute to the model.

While education level and number of births had positive significant values to the risk of worry, occupation status had negative significant values to the risk of worry. The OR indicated that women from lower education background were 2.162 times more likely than those from higher education background (reference category) to be at risk of worry. Meanwhile, the women who experienced pregnancy for the first-time were 2.049 times more likely than those who were multiparous (reference category) to be at major risk of worry.

The OR for the employment status indicated that employed women were at major risk of worry at about 2.656 times higher compared to unemployed (reference category) women. Other predictors (age, marital status, 
Table 3: Logistic Regression of Predictors (Demographic) Versus Antenatal Mental

\begin{tabular}{|c|c|c|c|c|c|c|c|c|}
\hline \multirow[b]{2}{*}{ Predictors } & \multicolumn{4}{|c|}{ DEPRESSION } & \multicolumn{4}{|c|}{ WORRY } \\
\hline & B & Wald & $p$ & OR (CI) & $\mathbf{B}$ & Wald & $p$ & OR (CI) \\
\hline Constant & -1.756 & 14.179 & $<0.001$ & 0.173 & -2.544 & 25.916 & $<0.001$ & 0.0079 \\
\hline Age: $<30$ years & -0.328 & 0.653 & 0.419 & $0.720(0.325,1.596)$ & -0.142 & 0.113 & 0.737 & $0.868(0.379,1.987)$ \\
\hline $\begin{array}{l}\text { Marital } \\
\text { Status: Single }\end{array}$ & 0.665 & 0.500 & 0.480 & $1.945(0.307,12.307)$ & -0.547 & 0.233 & 0.629 & $0.579(0.63,5.332)$ \\
\hline $\begin{array}{l}\text { Education } \\
\text { Level: } \\
\text { Lower }\end{array}$ & 1.007 & 8.227 & $* 0.004$ & $2.738(1.376,5.449)$ & 0.771 & 4.891 & $* 0.027$ & $2.162(1.092,4.283)$ \\
\hline Employed & -0.200 & 0.341 & 0.557 & $0.819(0.420,1.597)$ & 0.977 & 7.635 & $* 0.006$ & $2.656(1.328,5.311)$ \\
\hline $\begin{array}{l}\text { First-time } \\
\text { mother }\end{array}$ & 0.527 & 2.222 & 0.136 & $1.694(0.847,3.386)$ & 0.718 & 4.266 & $* 0.039$ & $2.049(1.037,4.048)$ \\
\hline $\begin{array}{l}\text { Gestation: } \\
<37 \text { weeks }\end{array}$ & -0.084 & 0.062 & 0.803 & $0.919(0.473,1.785)$ & 0.247 & 0.563 & 0.453 & $1.281(0.671,2.444)$ \\
\hline
\end{tabular}

and gestation) showed insignificant value $(\mathrm{p}>.05)$ and therefore did not contribute to the model. Analysis of logistics regression conducted show that the predictors (demographic variables) had no significance to anxiety.

Table 3 shows that the education level had positive significant values to the risk of depression. The odds ratio $(\mathrm{OR})$ reflected that the respondents from lower education background were 2.738 times more likely than those from higher education background to experience depression. Other predictors, however showed insignificant value $(p>.05)$ and therefore did not contribute to the model.

While education level and number of births had positive significant values to the risk of worry, occupation status had negative significant values to the risk of worry. The OR indicated that women from lower education background were 2.162 times more likely than those from higher education background (reference category) to be at risk of worry. Meanwhile, the women who experienced pregnancy for the first-time were 2.049 times more likely than those who were multiparous (reference category) to be at major risk of worry. The OR for the employment status indicated that employed women were at major risk of worry at about 2.656 times higher compared to unemployed (reference category) women. Other predictors (age, marital status, and gestation) showed insignificant value $(\mathrm{p}>.05)$ and therefore did not contribute to the model. Analysis of logistics regression conducted show that the predictors (demographic variables) had no significance to anxiety.
Table 4 shows that only 'worry' had negative significant values to social support. The OR indicated that women who were at major risk of worry required 0.141 times more social support than those who were not at major risk of worry. Meanwhile, other predictors (depressive and anxiety) showed insignificant value $(p>.05)$ and therefore did not contribute to the social support.

Table 4: Logistic Regression of Predictors (antenatal mental health disorder) versus Social Support

\begin{tabular}{|c|c|c|c|c|}
\hline \multirow[b]{2}{*}{ Predictor } & \multicolumn{4}{|c|}{ SOCIAL SUPPORT } \\
\hline & B & Wald & $p$ & OR \\
\hline Constant & 21.825 & 0.000 & 0.997 & 3009223926.307 \\
\hline $\begin{array}{l}\text { Depressive } \\
\text { symptoms: } \\
\text { At risk }\end{array}$ & -0.149 & 0.025 & 0.873 & 0.861 \\
\hline $\begin{array}{l}\text { Anxiety: } \\
\text { Presence }\end{array}$ & -17.453 & 0.000 & 0.997 & 0.000 \\
\hline $\begin{array}{l}\text { Worry: } \\
\text { Major worry }\end{array}$ & -1.960 & 4.550 & 0.033 & 0.141 \\
\hline
\end{tabular}

\section{DISCUSSION}

Various studies have been conducted to assess depression, anxiety and worry during pregnancy.28-30 This study assessed the association between these antenatal mental disorders and social support in one single study. The results indicated that $20.2 \%$ had depression symptoms, $22.5 \%$ had antenatal anxiety and $79 \%$ had antenatal worry. The prevalence rate reported in this study was comparable to other studies. ${ }^{13,28-29}$ The data obtained from 406 Māori antenatal women showed that $22 \%$ of them had depression and $25 \%$ had anxiety. ${ }^{29}$ A recent study in Malaysia also found that 
$20.3 \%$ of antenatal women experienced depression. ${ }^{13}$ A meta-analysis of five studies in Ethiopia suggested that the pooled prevalence of antenatal anxiety in Ethiopia was $21.28 \% .28$ The reported rate of worry among the antenatal women in this study was higher compared to the previous study. Signal et a ${ }^{29}$ found $13.6 \%$ of 426 pregnant women in New Zealand had antenatal worry. However, it should be noted that while they used Brief Measure of Worry Scale, this present study adopted CWS to measure worry during pregnancy. The use of different measures and study settings may contribute to differences in the reported prevalence. For instance, the prevalence of antenatal depression was lower when it was measured using EPDS compared to BDI and conducted in a community setting compared to institution-based setting. ${ }^{28}$

This study identified that working mothers, first-time mothers and decreased social support were associated with worry during pregnancy. While Gourounti et al. ${ }^{32}$ found that unemployment had a negative effect on worry during pregnancy, results of this study showed that unemployed women experienced less worry compared to employed women. The possible reasons were that working women had multiple tasks or were dissatisfied with their job, probably affecting their perception and thinking process throughout the pregnancy. First-time mothers in this study were found to be at risk of worry during pregnancy. A qualitative study by Bergbom et al. ${ }^{33}$ suggested that first-time mothers were concerned about the transformation from having a familiar body to a new body. Such transformation caused emotional discomforts, thus leading to the dissatisfactions with their own body. The first-time pregnant mothers are commonly young mother. Being young was identified as an independent risk factor for significant life stress and dysfunctional worry. ${ }^{29}$

The association between social support and antenatal anxiety was not confirmed by this study although previous studies had found significant associations between low social support and antenatal anxiety. $34-35$ The possible reason for this result was that the pregnant women had concealed their difficulties or problems from the others or that they did not regard social network as helpful. ${ }^{32}$
Although it is well-documented in the literature that there was an association between a lack of support and antenatal depression, the result from this present study does not support the previous findings. 9,13,20,33,37 Rashid and Mohd ${ }^{13}$ conducted a study among 3000 pregnant women attending antenatal clinics in Penang to determine the association between poor social support and antenatal depression. They found that poor social support was associated with the risk of antenatal depressive symptoms. However, antenatal worry was not studied in their study. This present study significantly adds to the body of knowledge about the the association between social support and worry in pregnancy. Findings from this study showed that decreased social support was associated with worry in pregnancy. The association between these two variables was not well established in the literature. However, it is believed that a lack of support from others, such as family and society may affect the pregnant women's emotions on the upcoming birth and thus lead to an increased worry. ${ }^{38}$

Current literature substantiates the identified association between various sociodemographic factors (e.g. a history of economic difficulties, poor marital relationships, history of stillbirth, complications during pregnancy, previous history of depression, unmarried status, and age group 20-29) and antenatal depression. 4,29,36,39 The factors did not hold significance in this study. Rather, this study found that only educational level was associated with antenatal depression. The expected negative effects of lower educational level on antenatal depression supported the results of the previous studies. $5,17,40$ Coll et al. ${ }^{5}$ found that maternal education was linked with higher EPDS scores among Southern Brazilian women, suggesting that a high educational level led to improved self-esteem and greater ability to control problematic situations, and resulting in a higher level of wellbeing.

Despite the vast literature reflecting the association between antenatal anxiety and maternal education, socioeconomic disadvantage, family history of depression or anxiety, disharmony in family relationship, and life satisfaction, ${ }^{5-6,12}$ this study is unable to support the existing evidence. Rather, this study is comparable 
to a study conducted among 212 antenatal women in Tanzania. ${ }^{41}$ Our findings support their argument that there should be a caution in generalizing data on antenatal anxiety from high-income countries to populations in LMIC like Malaysia.

The high rate of worry in this study calls for perinatal mental health screening and referral for clinical assessment, and supports a re-examination of perinatal mental health policy to ensure access to culturally responsive mental health care that meets women's needs. ${ }^{10}$ Whilst Depression, Anxiety and Stress Scale (DASS) has currently been applied to screen for perinatal mental health disorders in some of the Maternal and Child Health $(\mathrm{MCH})$ clinics in Malaysia, worry was not included within the scale. Therefore, a reliable screening tool that could lead to a comprehensive identification of antenatal mental disorders is needed. Such screening tool serves as a medium to prevent adverse impacts of antenatal mental disorders on maternal and child outcomes. ${ }^{36,39}$

This study has revealed that working mothers and first-time mothers are at high risk of worry during pregnancy, and women with lower education background are at higher risk of antenatal depression. For this reason, attention should be given to the women with these risk factors during antenatal education session provided throughout the antenatal follow-up in the clinics. The antenatal education not only reduces the fear of childbirth, but also decreases women's worry about labour by creating a positive perception about childbirth. ${ }^{14}$ Within the Malaysian healthcare setting, the sociodemographic status of an antenatal woman is identified during the antenatal booking, consequently providing an opportunity for healthcare professionals to identify the risk factors (working mothers, first-time mothers, lower educational level). Such identifications will lead to early intervention, and may mitigate the potentially negative consequences of worry during pregnancy and antenatal depression for maternal and child health. 5 Prevention of antenatal depression is important because without proper treatment and management, depression symptoms in pregnancy may persist after childbirth. A longitudinal study revealed that on average, $39 \%$ of those who experienced antenatal depression also experienced postnatal depression. Similarly, on average, $47 \%$ of those suffering postnatal depression had also experienced antenatal depression. ${ }^{42}$ Furthermore, social support element should be included in the intervention that targets working mothers, first-time mothers and women with lower educational level.

Whilst this study had determined the prevalence and factors associated with antenatal mental disorders, it had two limitations. First, this study used cross-sectional study design and the majority of the participants were married and of the Malay, thus the findings could not be generalized to antenatal women who was single, widowed, divorced, and of other races. Second, the lack of comparable studies in Malaysia and the absence of standardised screening tools used in assessing antenatal mental disorders among Malaysian women made it difficult to compare findings between studies.

\section{CONCLUSION}

This study has revealed that working mothers were at higher risk of antenatal depression whereas women with lower education background and first-time mothers were at risk of experiencing worry during pregnancy. Considering that the high level of worry in pregnancy could result in negative pregnancy outcomes and postnatal depression, clinical practice should include screening tools to measure psychological wellbeing of the antenatal women. Antenatal mental health requires at least as much attention and resources compared to that of the postnatal period. The element of social support should be included in the intervention that targets women with lower educational level, primiparous women and working mothers. This study has proven that social support plays a significant role in alleviating worry during pregnancy. Health care professionals should be trained in the detection and management of antenatal mental health disorders, such as depression, anxiety, and worry.

\section{REFERENCES}

1. Holditch-Davis D, Santos H, Levy J, et al. Patterns of psychological distress in mothers of preterm infants. Infant Behav Dev 2015; 41:154-163.

2. Gourounti K, Anagnostopoulos F, Lykeridou K, 
Griva F, Vaslamatzis G. Prevalence of women's worries, anxiety, and depression during pregnancy in a public hospital setting in Greece. Clin Exp Obstet Gynecol 2013; 40 (4):581-583.

3. Nagle-Yang S, Phillips M, Albaugh A, et al. Depression, Anxiety, and Attachment Among Women Hospitalized on an Antepartum Unit. Int J Psychiatry Med 2019; 54 (6):395-407.

4. Jha S, Salve HR, Goswami K, Sagar R, Kant S, Burden of Common Mental Disorders among pregnant women: a systematic review. Asian J Psychiatr 2018; 36:46-43.

5. Coll CVN, Silveira MF, Bassani DG, et al. Antenatal depressive symptoms among pregnant women: Evidence from a Southern Brazilian population-based cohort study. J Affect Disord 2017; 209:140-146.

6. Kang Y'T, Yao Y, Dou J,et al. Prevalence and Risk Factors of Maternal Anxiety in Late Pregnancy in China. Int J Environ Res Public Health 2016; 13(5): 468.

7. Heyningen TV, Myer L, Onah M, et al. Antenatal depression and adversity in urban South Africa. J Affect Disord 2019; 203: 121-129.

8. Kaiyo-Utete M, Dambi JM, Chingono A, Antenatal depression: an examination of prevalence and its associated factors among pregnant women attending Harare polyclinics. BMC Pregnancy and Childbirth 2020; 20:197.

9. Getinet W, Amare T, Boru B. Prevalence and Risk Factors for Antenatal Depression in Ethiopia: Systematic Review. Depression Research and Treatment, 2018.

10. Ogbo FA, Ezeh OK, Dhami MV et al. Perinatal Distress and Depression in Culturally and Linguistically Diverse (CALD) Australian Women: The Role of Psychosocial and Obstetric Factors. Int. J. Environ. Res. Public Health 2019, 16, 2945.

11. Tsakiridis I, Bousi2 V, Dagklis $T$, et al. Epidemiology of antenatal depression among women with high-risk pregnancies due to obstetric complications: a scoping review. Arch of Gynecol Obstet 2019, 300(4):849-859.

12. Maselko J, Bates L, Bhalotra S, et al. Socioeconomic status indicators and common mental disorders: Evidence from a study of prenatal depression in Pakistan. SSM - Population Health
2018, 4: 1-9.

13. Rashid A, Mohd R. Poor social support as a risk factor for antenatal depressive symptoms among women attending public antenatal clinics in Penang, Malaysia. Reprod Health 2017; 14:144

14. Yuvaci HU, Cinar N, Caka DY, et al. Effects of antepartum education on worries about labor and mode of delivery. J Psychosom Obstet Gynaecol $2020 ; 12 ; 1-7$.

15. Abdi F, Navidpour F, Dolatian M, A Literature Review Of PregnancyWorries and Stress Scales Iran J Psychiatry Behav Sci 2018; 12(3):e14581.

16. Fadzil A, Balakrishnan K, Razali R, Sidi H, Malapan $\mathrm{T}$, et al. Risk factors for depression and anxiety among pregnant women in Hospital Tuanku Bainun, Ipoh, Malaysia. Asia-Pac Psychiat. 2013; 5:7 -13 .

17. Ghaffar R, Iqbal Q, Khalid A, Saleem F, Hassali M, et al. Frequency and predictors of anxiety and depression among pregnant women attending tertiary healthcare institutes of Quetta City, Pakistan. BMC Women's health 2017; 17 (1):51.

18. Biratu A, Haile D. Prevalence of antenatal depression and associated factors among pregnant women in Addis Ababa, Ethiopia: a cross-sectional study Reprod Health 2015; 12 (99).

19. Senturk V, Abas M, Dewey M, Berksun O. Antenatal depressive symptoms as a predictor of deterioration in perceived social support across the perinatal period: a four-wave cohort study in Turkey. Psychol Med 2017; 47 (4):766-775.

20. Milgrom J, Hirshler Y, Reece J. Social Support-A Protective Factor for Depressed Perinatal Women? Int. J. Environ Res Public Health 2019; 16, 1426

21. Ng CG, Amer Siddiq AN, Aida SA, Zainal NZ, Koh OH. Validation of the Malay version of the Multidimensional Scale of Perceived Social Support (MSPSS-M) among a group of medical students in Faculty of Medicine, University Malaya. Asian J Psychiatr. 2010 Mar;3(1):3-6.

22. Zimet GD, Dahlem, NW, Zimet SG, Farley GK. The Multidimensional Scale of Perceived Social Support. J. Pers. Assess 1988; 52 (1): 30-41.

23. Wan Mohd Rushidi, WM, Amir A, Mahmood Nazar M. (2003) Revalidation of the Malay version of the Edinburgh Postnatal Depression Scale (EPDS) among Malay postpartum women attending 
the Bakar Bata Health Center in Alor Setar, Kedah, Northwest of Peninsular Malaysia. Malays J Med Sci, 10 (2), pp. 71-75.

24. Cox JL, Holden JM, Sagovsky R. Detection of postnatal depression. Development of the 10-item Edinburgh Postnatal Depression Scale. Br J Psychiat 1987; 150 (6):782-786.

25. Hashim E, Wan Hasyila WO, Ang YH, Azlan Helmy AS, Husyairi H.

26. Psychometric Properties of the Malay Translated Spielberger State-Trait Anxiety Inventory in Exploring Parental Anxiety. Med Health 2018,13 38. (1).

27. Spielberger CD, Gorsuch RL, Lushene R, Vagg PR, Jacobs GA. Manual for the State-Trait Anxiety Inventory. 1983. Palo Alto, CA: Consulting Psychologists Press.

28. Green JM, Kafetsios K, Statham HE, Snowdon CM. Factor structure, validity and reliability of the Cambridge Worry Scale in a pregnant population. J. Health Psychol 2003; 8: 753-764.

29. Ayano G, Tesfaw G, Shumet S. Prevalence and determinants of antenatal depression in Ethiopia: A systematic review and meta-analysis. PLoS ONE 2019; 14(2): e0211764.

30. Signal TL, Paine SJ, Sweeney B. et al. The Prevalence of Symptoms of Depression and Anxiety, and the Level of Life Stress and Worry in New Zealand Māori and non-Māori Women in Late Pregnancy. Aust N Z J Psychiatry 2017; 51 (2):168-176.

31. Kane HS, Dunkel Schetter C, Glynn LM, Hobel CJ, Sandman CA. Pregnancy anxiety and prenatal cortisol trajectories. Biol Psychol 2014; 100:13-9.

32. Teate AJ. From worry to hope: An ethnography of midwife-woman interactions in the antenatal appointment, PhD Thesis, April 2018.

33. Gourounti K, Anagnostopoulos F, Sandall J. Poor marital support associate with anxiety and worries during pregnancy in Greek pregnant women. Midwifery 2014; 30 (6):628-35.

34. Bergbom I, Modh C, Lundgren I, Lindwall L. First -time pregnant women's experiences of their body in early pregnancy, Scand J Caring Sci 2016; 31 (3):579-586.

35. Biaggi A, Conroy S, Pawlby S, Pariante CM. Identifying the women at risk of antenatal anxiety and depression: A systematic review, J Affect Disord 2016; 191, February: 62-77.

36. Bayrampour $\mathrm{H}$, Vinturache A, Hetherington E, Lorenzetti DL, Tough S. Risk factors for antenatal anxiety: A systematic review of the literature. J Reprod Infant Psychol 2018; 36 (5).

37. Dadi AF, MillerI ER, Mwanri L. Antenatal depression and its association with adverse birth outcomes in low and middle income countries: A systematic review and meta-analysis PLoS ONE 2020; 15(1): e0227323.

. Anderson FM, Hatch SL \& Comacchio C et al. Prevalence and risk of mental disorders in the perinatal period among migrant women: a systematic review and meta-analysis. Arch Womens Ment Health 2017; 20:449-462

39. Ternström E, Hildingsson I, Haines H, Rubertsson C. Pregnant women's thoughts when assessing fear of birth on the Fear of Birth Scale. Women Birth 2016; 29 (3):e44-49.

40. Dadi AF, Miller ER, Bisetegn TA. Global burden of antenatal depression and its association with adverse birth outcomes: an umbrella review. BMC Public Health 2020; 20:173.

41. Aktas S, Calik KY. Factors affecting depression during pregnancy and the correlation between social support and pregnancy depression. Iranian Red Crescent Medical Journal 2015; 17 (9): e16640.

42. Wall V, Premji SS, Letourneau N, et al. Factors associated with pregnancy-related anxiety in Tanzanian women: a cross sectional study. BM] Open 2018; 8:e020056.

43. Underwood L, Waldie K, D’Souza S. A review of longitudinal studies on antenatal and postnatal depression. Arch Womens Ment Health 2016; 19 (5):711-20. 